46

47

48

49

50

\title{
Limiting-stress-elimination hypothesis: approach to increase savanna cowpea productivity \\ by stress reduction
}

\author{
Acheampong Atta-Boateng" and Graeme P. Berlyn
School of Forestry and Environmental Studies, Yale University, New Haven, CT 06511, USA \\ Acheampong Atta-Boateng" and Graeme P. Berlyn
School of Forestry and Environmental Studies, Yale University, New Haven, CT 06511, USA
}

"Corresponding author email: acheampong.atta-boateng@plants.ox.ac.uk

"Comesponding a her enal: acheampongatta-boteng@plans.oxac.uk 


\section{Abstract}

56 We propose and test the Limiting-Stress-Elimination Hypothesis (LSEH), as a decision axiom to guide in

57 determining the optimal intervention strategy towards yield allocation in a savanna legume. We

58 considered osmotic stress and soil nitrogen $(\mathrm{N})$ limitation, which both characterize Guinea savanna agro-

59 ecozone. We hypothesized that biomass allocation will increase when the limiting stress is eliminated at

60 least until the next limiting stress impacts yield. We assessed responses of Vigna unguiculata (L.) Walp

61 (cowpea) to osmotic stress treatments (non-hormonal biostimulant and exogenous metabolite) and $\mathrm{N}$

62 input by leaf level physiology, N-fixing capacity and biomass. The relative increase in biomass (\%), and

63 pod yields reveal that osmotic stress (45\%) more than nitrogen (13\%) is limiting to cowpea growth under

64 Guinea savanna conditions, although $\mathrm{N}$ fertilization increased nodulation and maximized PSII quantum

65 yield. In the Sprengel-Liebig's decrement from the maximum concept, the decrement from the maximum

66 for each stressor must be minimized in order to produce the absolute maximum production. However, this

67 may not be economically feasible in many situations. Conversely, LSEH demonstrates that significant

68 productivity is attainable by eliminating a relatively more limiting stress, osmotic stress, regardless of the

69 limitation and natural demand for the relatively less limiting $\mathrm{N}$ in leguminous cowpea in the savanna. 


\section{1. Introduction}

85 Sustainably overcoming food insecurity amid climate threats and rising global population require careful

86 strategic interventions in crop production (Tilman et al., 2002). Soil fertilization significantly impacts

87 global food production even after the discovery of Haber-Bosch nitrate synthesis in the early $20^{\text {th }}$ century

88 (Erisman et al., 2008). The ability to produce synthetic nitrates made nitrogen fertilizers readily

89 available. Unfortunately, the prolonged or the overuse of inorganic nitrogen fertilizer is unsustainable,

90 disruptive of the $\mathrm{N}$-cycle in ecosystems, and thereby negatively impacting the environment (Kinzig P.

91 Ann, Socolow, 1994; Vitousek et al., 1997). This has led to high advocacy for scientific advances and

92 policy changes which control the environmental impacts of agriculture (Tilman, 2001).

93 Increasing legume production is a long-term sustainable soil amendment strategy that could further

94 contribute to ameliorating nutritional gaps in protein diet, particularly in low-income economies such as

95 sub-Sahara Africa (Dakora and Keya, 1997; Duranti and Gius, 1997). In sub-Sahara Africa, the tropical

96 savanna landscape is characterized by low soil nitrogen, high ambient temperature, and drought all of

97 which impede crop production. While several resources tend to limit plant growth simultaneously under

98 natural conditions (Chapin et al., 1987), soil fertilization remains the advocated intervention to improve

99 crop yield in savanna agriculture (FAO, 2005; Martey et al., 2013). However, soil fertilization in the

100 absence of government subsidies and international aid programs could further increase the cost burden of

101 farming on low-income farmers. Moreover, a large percentage of inorganic fertilizer leaches down into

102 the subsoil where is not taken up by the crop plants making this expenditure less efficient. Furthermore,

103 fertilizer application does not necessarily address the critical challenges that confront field-grown crops.

104 Although nitrogen fixation offers leguminous plants a competitive advantage in savanna ecosystems,

105 nitrogen $(\mathrm{N})$ fertilization is long known to decrease $\mathrm{N}$-fixing rates in legumes (McAuliffe et al., 1958;

106 Salvagiotti et al., 2008). However, it is unclear whether N-fertilization is the optimal intervention for

107 improving legume mono cropping under savanna climate, given the importance of $\mathrm{N}$-availability in

108 legume development.

109 The functional relevance of $\mathrm{N}$ during legume development underscores the need for investment in

110 securing allocation from pooled sugar resources. Legumes allocate photoassimilates to symbiotic

111 microbes under limited soil $\mathrm{N}$ conditions, to increase $\mathrm{N}$-fixation rates. Likewise, during abiotic stress,

112 plants convert photoassimilates into protective metabolites such as compatible solutes (osmoprotectants)

113 to alleviate stress impacts such as the evolution of reactive oxygen species under drought conditions.

114 Consequently, both abiotic stress response and nitrogen needs in savanna legumes may eventually

115 compete from a common carbon resource pool. 
116 These facts underpin the importance of allocation decision in plants (Lerdau and Gershezon, 1997);

117 support the need to re-assess, and test existing theories to ascertain and inform intervention in situations

118 where both nitrogen limitation and abiotic stressors represent the reality in field conditions as pertain in

119 the sub-Saharan Guinea savanna.

120 According to the Resource Availability Theory (RAT), plant species in low resourced environments

121 invest in defensive allocation (Coley et at. 1985) such as the synthesis of compatible solutes from sugars

122 as a trade-off to growth. On the contrary, the Growth Differentiation Balance Hypothesis, GDBH

123 (Loomis, 1932) is based on a higher physiological sensitivity towards growth such that allocation favors

124 growth. For instance, as in the case of nitrogen limitation where excess photoassimilates are allocated

125 towards plant defense. A bridging or intermediate theory of the two is the Carbon-Nutrient Balance

126 Hypothesis, CNBH (Bryan et al. 1983) which advances that more carbon, for instance, is allocated under

127 nitrogen limitation to both acquire more nitrogen and protect nitrogen resources. While ecological

128 theories encapsulate the behavior of natural ecosystems, agricultural practices or interventions may not,

129 particularly in the case of species self-regeneration and biotic competition. Rather, agriculture remains a

130 major land use threat to natural ecosystems yet, an indispensable basic support of human survival. In

131 essence, agroecology as a sustainable agronomic practice can be consistent with predictable ecological

132 patterns to ascertain predicable outcomes. Although crop production often tends to be monoculture, a

133 monoculture agronomy in itself is comprehensible from an ecological point of view as a single species

134 interacting with each other in disturbed growing space. Agronomic interventions that seek to optimize the

135 crop-environment feedback dynamics towards desirable productive outcomes can implement this

136 perspective. Of particular interest is how legumes partition resource allocation when growth conditions

137 demand multiple needs such as $\mathrm{N}$-fixation and drought stress responses.

138 Where grain yield is the primary goal of the agronomist, intervention strategies for crop development that

139 regulate responses can utilize knowledge of legume allocation strategies.

$140 \mathrm{~N}$-fixation capacity is an adaptation to higher nitrogen need in legumes and/or serves as a competitive

141 trait over non-leguminous species in N-limited environments. Under limited soil N, increased N-fixation

142 response is expected. Where field conditions necessitate, legumes may employ additional responses to

143 deal with different environmental stresses (Bryan et al., 1996). This may increase demand on pooled

144 carbon resources, possibly resulting in a share or shift in carbon allocation towards more vulnerable or

145 demanding sinks. Deciphering the limiting stress factor under multiple-stress conditions is essential for

146 developing efficient and cost-effective agroecological interventions for stressful environments.

147 In this paper, we propose the Limiting-Stress-Elimination Hypothesis (LSEH) and test it using non-

148 hormonal biostimulant, varied concentrations of a polyol-based leaf osmoprotectants as exogenous

149 metabolites and nitrogen fertilizer as interventions to cowpea response under Guinea savanna conditions. 


\subsection{Hypothesis}

153 LSEH assumes that plants exposed to multiple physiological stressors will relatively show higher

154 physiological sensitivity and eventually, increased productivity when an intervention

155 eliminates/ameliorates the most limiting stress. This hypothesis stems from Carl Sprengel and Justus von

156 Liebig's Law of the Minimum which states that growth is controlled by the limiting factor or scarcest

157 resource (Liebig, 1840; van der Ploeg et al., 1999). Agronomic intervention(s) here refers to intended

158 action(s) that remedies condition(s) that impair crop plant productivity. Thus, under multi-stress scenarios

159 where a plant is constrained by more than one stress factor, an intervention that eliminates the most

160 threatening stressor may likely alleviate the stress and maximize productivity when it is economically

161 impractical to eliminate all prevailing stressors.

162 On the decrement from the maximum hypothesis (Mitscherlich, 1909), maximum productivity requires

163 relieving all decrements from the optimal level for each nutrient, but we can use the term stressor as

164 mineral nutrients are not the only stressors that limit productivity.

165 Particularly in the Guinea savanna of West Africa, where leguminous crops are predominantly

166 constrained by limited soil nitrogen and osmotic stressors (Fig. 1), the simultaneous treatment to

167 eliminate multiple abiotic stressors may increase farming costs beyond economic practicality.

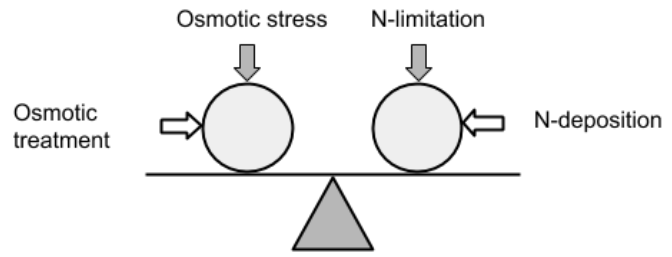

Fig 1. A schematic of the limiting-stress-elimination hypothesis (LSEH). Vertical arrows represent

172 imposed stress (Osmotic stress and $\mathrm{N}$ limitation). Horizontal arrows indicate applied intervention

173 (osmoregulation and nitrogen deposition). Circles represent plant organism. Balanced plane implies a

174 notion of significance or pedigree of stress impact. At equilibrium, the stressor impact on productivity is

175 assumed similar. Without any intervention, stress impact is can be assumed synergetic or difficult to

176 detect. However, when defined interventions are simultaneously applied, a shift in slope or tilt

177 distinguishes the relative magnitude of stressor and limiting growth factor. 
Although legumes can biologically fix N, they depend on prior invested carbon reserves much as a metabolic response to osmotic stress. The LSEH hypothesizes that, eliminating a relatively more threatening stress among multiple stresses, will increase productivity more than alleviating a relatively less threatening stress. Yet again, there is the question of how the more limiting stress is determined under

186 field conditions?

187 In this study, we determine the limiting stress by testing which stress intervention favors higher

188 productivity in cowpea based on biomass allocation and stress response strategy. Further, we examine

189 how results relate or support existing allocation theories. Then we evaluate the implication of the

190 proposed LSEH on leguminous crop production in economically and environmentally resource

191 challenged sub-Saharan savanna.

\subsection{Materials and methods}

194 Here we describe how we experimentally tested hypothesis with cowpea in the Guinea savanna agroecological of zone in Ghana, West Africa.

\subsection{Study area}

198 The Northern region covers $40 \%$ of Ghana's $\left(92,456\right.$ sq. mile; latitudes $\left.4-12^{0} \mathrm{~N}\right)$ land cover by area. Two major ecological zones characterize the region: the sub-humid to semi-arid Guinea savanna and the arid Sudan savanna zones (Gyasi 2015). The Inter-Tropical Conversion Zone controls rainfall seasons in Ghana with one wet season in the north and two wet seasons in the south. Low, erratic rainfall ranging between 150-250 mm/month in a single dry season to $1100-1200 \mathrm{~mm} / \mathrm{month}$ in a single wet season characterizes the study area. Mean monthly temperature during the growing season ranges between 26-30 ${ }^{0} \mathrm{C}$ (Buah and Mwinkaara 2009). Although the study was conducted at the onset of the growing season, the total rainfall recorded during the study depicts a typical Guinea savanna dry season weather (Table 1).

Table. 1 Weather records and soil texture composition of experimental site

\begin{tabular}{|l|l|l|l|}
\hline \multicolumn{2}{|c|}{ Weather } & \multicolumn{2}{l|}{ Soil composition (\%) } \\
\hline Total rainfall (mean) & $203.8(6.6) \mathrm{mm} /$ day & Sand & 55.8 \\
\hline Average sunshine & $5.8 \mathrm{Hrs}$ & Silt & 41.96 \\
\hline Average mean Temp & $26.7^{0} \mathrm{C}$ & Loam & 2.2 \\
\hline
\end{tabular}




\begin{tabular}{|l|l|l|l|}
\hline (Max|Min) & $(29.7 \mid 23.6)^{\circ} \mathrm{C}$ & & \\
\hline $\begin{array}{l}\text { Average mean RH } \\
\text { (Min|Max) }\end{array}$ & $\begin{array}{l}84 \% \\
(93 \mid 75) \%\end{array}$ & & \\
\hline
\end{tabular}

Beneath the surface soil is a shallow depth of cemented layer of iron pan and savanna ochrosols. The soil is humus-deficient due to low organic matter content from sparse vegetation. Iron pan impedes water

211 penetration causing water logging in the peak rainy season and complete drying in the dry season. Hence,

212 soil nutrient availability is a major constraint for agricultural production (Runge-Metzger and Diehl 1993;

213 Gyasi 1995).

\section{$214 \quad 2.2$ Preparation of field, plants and treatments}

215 Three experimental blocks, each containing four distinct raised soil beds of dimension $2 \mathrm{~m} \times 8 \mathrm{~m}$ each and

216 interspaced by a meter gap were prepared across a slope in a series-like fashion. Each bed in a block

217 represented a treatment group based on a Randomized Complete Block Design.

218 Each bed was seeded with cowpea (IT97K-499-35, Songotra) and later thinned to 40 plants per bed after

219 germination at $80 \mathrm{~cm} \times 40 \mathrm{~cm}$ spacing. Treatments were assigned randomly within and between blocks.

220 Given the conditions of Guinea savanna, we will use the term osmotic stress to represent both drought

221 and heat stress due to their occurrence duality (Dwivedi et al., 2018) or specifically to represent

222 conditions such as low soil moisture, atmospheric vapor pressure deficit and salinity for their similarity in

223 physiological responses (Chaves et al, 2009; Munns 2002). The first osmotic treatment constituted two

224 different concentrations; 0.25g/L (HH25) and $0.5 \mathrm{~g} / \mathrm{L}$ (HH50) of the osmolytic polyol, Hexane 1, 2,3,4,5,

225 6-Hexol $\left(\mathrm{C}_{6} \mathrm{H}_{14} \mathrm{O}_{6}\right)$ of molecular weight $182.17 \mathrm{~g} / \mathrm{mol}$ obtained from Sigma Alderich Co. These represent

226 separate treatment groups for statistical convenience. In addition, a non-hormonal biostimulant (Biost.)

227 comprising as osmotic stress treatment, made up of; 2-Amino-5-guanidinopentanoic acid, L-ascorbic acid,

228 thiamine (3-[(4-Amino-2-methyl-5-pyrimidinyl) methyl]-5-(2-hydroxyethyl)-4-methyl-1,3-thiazol-3-ium

229 nitrate) and cis-1, 2, 3, 5-trans-4, 6-cyclohexanehexol (myoinositol). The formulation was developed

230 separately in the lab based on several allocation and yield trials in glasshouse experiments on allocation

231 study model plant, Raphinus sativus.

232 Further, $5 \mathrm{~g} / \mathrm{L}$ nitrogen was prepared from $98 \%$ ammonium nitrate $\left(\mathrm{NH}_{4} \mathrm{NO}_{3}\right)$ as inorganic nitrogen

233 treatment (N Fertiliser). All controls groups were treated with distilled water. Each plant replicate

234 received $50 \mathrm{~cm}^{3}$ of treatment dose biweekly until the onset of pod formation. Nitrogen was applied 
directly to the soil around the stem of plants while $H H 25, H H 50$, Biost. in addition, control were each applied to both foliage and soil.

\subsection{Plant sampling and measurement}

240 To minimize the influence of growth defects, 15 best germinates out of 40 ranging $\sim 9-11 \mathrm{~cm}$ in height 241 were tagged after establishment. Leaf measurements were conducted during active photosynthetic period 242 in the morning (PPDF ranged from 900-1200 $\mathrm{m} \mathrm{molm}^{-2} \mathrm{~s}^{-1}$ ). The Leaf temperature, chlorophyll

243 fluorescence and chlorophyll concentration of the youngest fully expanded leaf of each tagged plant was

244 measured two weeks after treatment during the vegetative, flowering and podding growth phases of 245 cowpea.

\section{Biomass and Nitrogen-fixing trait}

248 Whole plants were carefully removed from soil bed, the soil debris gently brushed off. Root nodules per 249 plant were carefully removed, counted, weighed and re-weighed after oven drying to a constant weight at $250 \quad 60{ }^{\circ} \mathrm{C}$ to obtain total weight of nodule per plant and total number of nodules formed per plant. Means for 251 each treatment groups are reported in section 3. Furthermore, whole plants with intact pods were oven 252 dried to constant weight to obtain total biomass, then followed by separate measurement of pods.

255 Leaf temperature, $T_{l}$ was measured as an indicator of plant stress (Carroll et al., 2017; Rodríguez et al., 256 2015; Udompetaikul et al., 2011). Variations in moisture stresses are known to significantly alter leaf 257 temperature, causing it to deviate from ambient temperature (Wiegand and Namken, 1966). $T_{l}$ was 258 measured by a laser guided infrared thermometer (ST60 ProPlus ${ }^{\mathrm{TM}}$ Raytec, USA) with 30:1 optical 259 resolution, $-30{ }^{0} \mathrm{C}-600{ }^{0} \mathrm{C}$ temperature range, $8-12 \mu \mathrm{m}$ spectral responses at $500 \mathrm{msec}$, and 0.10-1.0 260 emissivity. The device collects and focus energy optically emitted, reflected, and transmitted by the leaf 261 surface on a detector, then converts to ambient temperature readings in ${ }^{0} \mathrm{C}$ with $0.07{ }^{0} \mathrm{C}$ error margin.

Chlorophyll fluorescence,

264 The stress manifested in plants can be determined by observing the leaf photosystem II (PSII), which is a 265 protein complex in the light dependent reactions of plant photosynthesis. PSII damage is the first 266 manifestation of stress in plant leaves (Maxwell and Johnson, 2000) and the efficiency of this state is 267 referred as photochemical efficiency. Maximum quantum yield at PII is determined based on the 
fluorescence ratio, $F_{v} F_{m}^{-1}$, a well-studied phenomenon in plant physiology (Rodríguez et al., 2015) and well established physiological indicator of plant tolerance to environmental stress including drought and heat (Dwivedi et al., 2018; Maxwell and Johnson, 2000). Plant stress that affects the photosystem II is determined based on a calculated variable fluorescence $\left(F_{v}\right)$ to maximal fluorescence $\left(F_{m}\right)$ ratio, using a chlorophyll fluorescence device (model OS-30p, Opti-Sciences, Inc.). To measure $F_{v} F_{m}^{-1}$, leaf samples were dark-adapted by placing leaves inside plastic cuvettes that prevented light incidence on the leaf for 30 minutes to excite pre-photosynthetic antenna by a weak modulated light. At this stage, photosystems II are maximally oxidized and the minimal fluorescence, $F_{0}$, was measured. On light saturation at maximum light exposure, the maximum fluorescence, $F_{m}$, was determined and $F_{v} F_{m}^{-1}$ calculated as:

$$
\frac{F_{v}}{F_{m}}=\frac{F_{m}-F_{0}}{F_{m}}[1]
$$

Where $F_{v}=F_{m}-F_{0}$ is the variable fluorescence.

\section{Chlorophyll content}

Leaf chlorophyll content is a physiological trait associated with drought and heat stress (Dwivedi et al., 2018). A handheld chlorophyll-detecting device, SPAD-502 (Konica Minolta Inc.), measured leaf chlorophyll. Leaf was placed in between an attached in between a receptor window and a measuring head on which is pressed to measure chlorophyll at 650 and $940 \mathrm{~nm}$ in SPAD units at \pm 1.0 accuracy (see

286 Richardson, et al, 2002).

\subsection{Statistical assumption}

289 The null hypothesis $\left(\mathrm{H}_{\mathrm{o}}\right)$, no differences in population means: $T_{1}=T_{2}=T_{3}=T_{4} ; \mathrm{P}=0.05$.

290 The null hypothesis $\left(\mathrm{H}_{\mathrm{o}}\right)$, no differences in population means: $T_{1}=T_{2}=T_{3}=T_{4} ; \mathrm{P}<0.05$, where $T_{n}$ 291 indicates treatment type $n$.

\subsection{Statistical analysis}

294 The Lme4 package in R (Bates et al., 2015) was used to perform Mixed Effect Modelling (MEM) by 295 restricted maximum likelihood t-tests. MEM performs ANOVA on repeatedly measured variables and 296 estimates fixed and random sources of variation. To know where significant differences occurred, we 
tested general linear hypotheses by multiple pairwise comparisons of means based on Tukey HSD tests on normally distributed data. All statistical analyses were conducted using the R programming language and environment (R Core Team).

\subsection{Results}

\subsection{Effect of treatments on biomass, podding capacity and root nodulation}

Mean biomass of treated cowpea was significantly different $(\mathrm{P}<0.001$, Table 2$)$. Non-hormonal biostimulant had highest biomass output, 45\% followed by HH25 (17\%), HH50 (13.3\%), N Fertilizer $(13.1 \%)$ and controls. Nodulation capacity, determined by means of the total number of nodules formed per cowpea was significantly different $(\mathrm{P}<0.01)$ among treatment groups. $\mathrm{N}$ treated cowpea relatively formed the highest number of nodules per root as well as the highest nodule weight (Fig 2, c \& d). Thus, we reject the null hypothesis that there is no difference in the mean effect of administered treatment interventions on cowpea growth with respect to biomass and nodulation capacity.
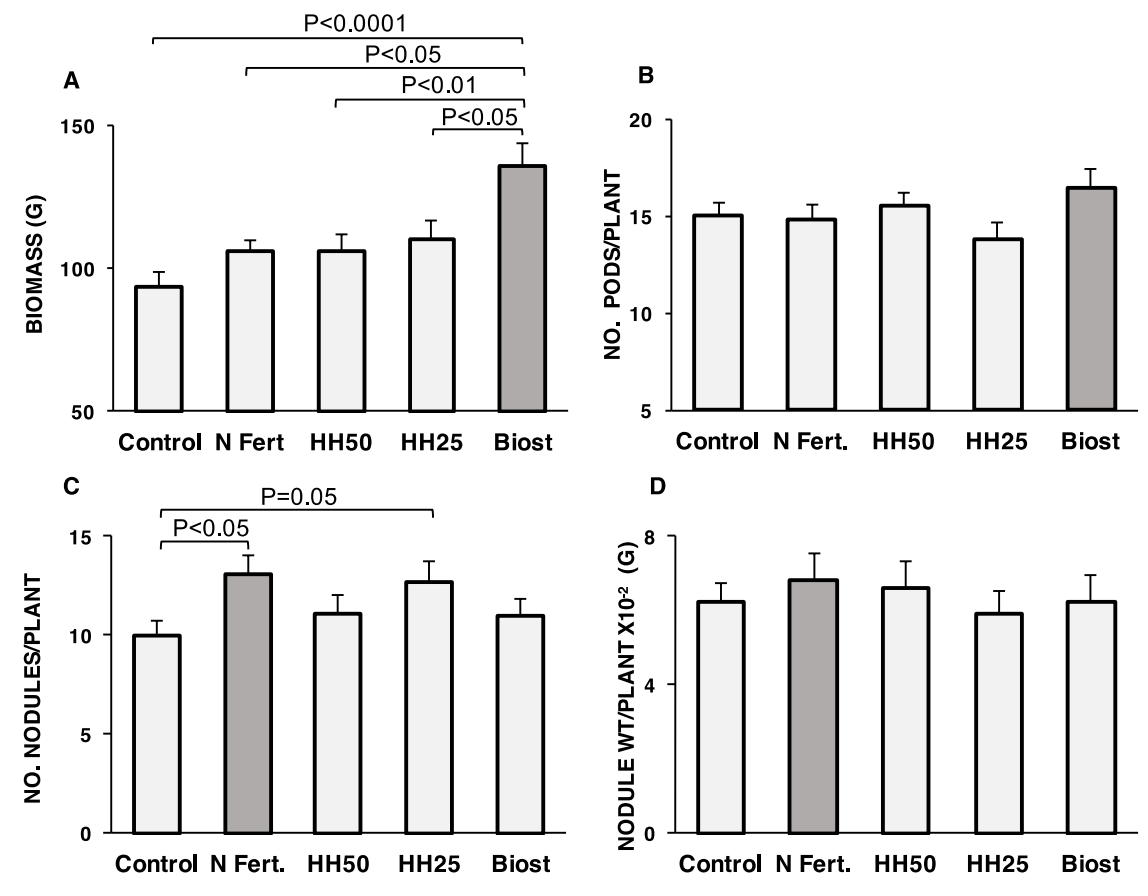

TREATMENTS

312 Fig 2. Means of total biomass, grams/plant (A), mean number of pods per plant (B), mean number of root

313 nodules formed by roots per plant (C) and mean weight of root nodule per plant (D) in response to 
314 cowpea treatments; control, N Fertilizer (N Fert), sorbitol (HH25 \& HH50) and non-hormonal

315 Biostimulant (Biost). P-values on bars indicate Tukey HSD significance between paired groups.

318 Table 2. Summary ANOVA of mean response of treatment groups.

\begin{tabular}{|c|c|c|c|c|c|c|c|}
\hline Variables & DF & $\begin{array}{l}\text { Sum } \\
\text { square }\end{array}$ & Mean square & F value & $\operatorname{Pr}(>\mathbf{F})$ & significanc & $\begin{array}{l}319 \\
320\end{array}$ \\
\hline \multicolumn{8}{|l|}{ Biomass } \\
\hline Treatment & 4 & 38452 & 9613 & 6.1889 & $<0.0001$ & $* * *$ & 321 \\
\hline Blocks & 2 & 15246 & 7623 & 4.907 & 0.0082 & $* *$ & 322 \\
\hline No. of pods & & & & & & & 323 \\
\hline Treatment & 4 & 173 & 43.31 & 1.598 & 0.1759 & $\mathrm{~ns}$ & \\
\hline Blocks & 2 & 228 & 113.9 & 4.207 & 0.016 & $*$ & 324 \\
\hline Nodule mass & & & & & & & 325 \\
\hline Treatment & 4 & 0.0018 & 0.00046 & 0.414 & 0.798 & $\mathrm{~ns}$ & 326 \\
\hline Blocks & 2 & 0.1865 & 0.0932 & 83.59 & $<0.0001$ & $* * *$ & \\
\hline \multicolumn{8}{|l|}{ No. of nodules } \\
\hline Treatment & 4 & 307 & 76.8 & 3.413 & 0.009 & $* *$ & 328 \\
\hline Blocks & 2 & 2487 & 1243 & 55.2 & $<0.0001$ & $* * *$ & 329 \\
\hline
\end{tabular}

331 The treatment effects on both the mean number of pods formed per cowpea and mean nodule mass per 332 cowpea root nodules were not significant $(\mathrm{P}>0.05$, Table 2). However, the shows non-hormonal 333 biostimulant treatment relatively yielded more pods per plant.

\section{$334 \quad 3.2$ Effect of treatments on leaf physiological responses}

335 The mean effect of treatments on leaf chlorophyll content in cowpea did not differ significantly, however, 336 the difference $(\mathrm{P}=0.05)$ in leaf chlorophyll responses to $\mathrm{HH} 25$ and $\mathrm{HH} 50$ indicates that the concentration 337 of exogenous leaf osmoprotectants is important to chlorophyll response in savanna cowpea. Maximum 338 quantum yield, $F_{v} F_{m}^{-1}$, in response to $\mathrm{N}$ differed significantly from osmotic treatments and controls 
339 (Table 3). Leaf temperature, $T_{l}$ significantly declined in $\mathrm{N}$ fertilized cowpea relative to controls and osmotic stress treatment groups (Fig 3c, Table 3).

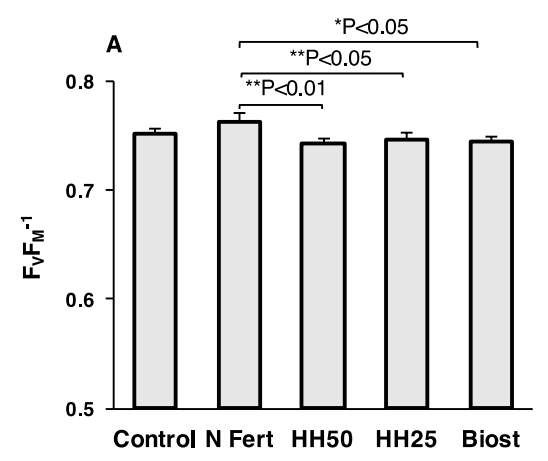

343 Fig 3. Leaf physiological response of cowpea to osmotic treatments (HH25, HH50 and Biost) and N

344 treatment (N Fert.). Bar graphs represents total oven dry biomass (A), leaf chlorophyll content (B),

345 chlorophyll fluorescence ratio (C) and leaf temperature (D).

347 Table 3. Significant pairs from multiple mean comparisons based on Tukey HSD test from a linear Mixed 348 Effect model fit. Except reported, all other possible mean-pairs were not significant.

\begin{tabular}{|c|c|c|c|c|c|}
\hline Parameter variables & Estimate & Std error & $z$ value & $\operatorname{Pr}(>|z|)$ & significance \\
\hline \multicolumn{6}{|l|}{$\mathrm{FvFm}^{-1}$} \\
\hline Fertilizer-Biost & 0.0368 & 0.0128 & 2.859 & 0.033 & $*$ \\
\hline Fertilizer-HH25 & -0.0333 & 0.0113 & -2.926 & 0.028 & $*$ \\
\hline Fertilizer-HH5O & -0.0399 & 0.0113 & -3.506 & 0.004 & $* *$ \\
\hline
\end{tabular}

Chlorophyll content

$$
\text { HH25-HHS5O } \quad-2.5979 \quad 1.0300 \quad-2.522 \quad 0.05
$$

Leaf temperature, $T_{l}$ 


$\begin{array}{cccccc}\text { Fertilizer-Biost } & -1.1436 & 0.2867 & -3.989 & <0.001 & * * * \\ \text { Fertilizer-control } & -1.3616 & 0.2554 & -5.345 & <0.001 & * * * \\ & & & & & * \\ \text { Fertilizer-HH25 } & 0.7694 & 0.2548 & 3.020 & 0.021 & * \\ \text { Fertilizer-HH50 } & 0.9004 & 0.2548 & 3.534 & 0.003 & * * *\end{array}$

350 For evaluating the effect of cowpea treatment with respect to stress response, we show the underlining 351 relationship between selected indicators from our study data (Fig 4).

\subsection{Discussion}

\section{4.1 Biomass and physiological responses of cowpea to osmotic and $\mathbf{N}$ treatments}

355 Cowpeas cultivated in the savanna are exposed to multiple environmental stressors. Environmental

356 stressors in the context of the plant-environment-feedback nexus, shape the fundamental developmental

357 trajectory and productive success of plants. In cowpea production, low soil fertility and drought

358 constitutes abiotic factors that constrains production (Roberts, 2013). Although legumes are adapted to

359 low $\mathrm{N}$ conditions, N-fixation comes at a cost. Under savanna conditions, other competing abiotic factors

360 may inevitably constrain biological N-fixing capacity of nodulating legumes, and consequently limit their

361 productivity. Hence, we hypothesized that where cowpea is constrained by multiple factors, elimination

362 of the relatively more limiting factor will result in relative increased productivity. We measured

363 productivity by total biomass output, complemented by pod yield. Given relatively higher biomass, pod

364 yield and less investment in root nodules in osmotic treated cowpea, we conjecture that osmotic stress is

365 more limiting than N-limitation in Guinea savanna cowpea.

366 In this study, a healthy physiological status is attributable to higher chlorophyll content, $F_{v} F_{m}^{-1}$ and lower

367 leaf temperature (Fig 4). 

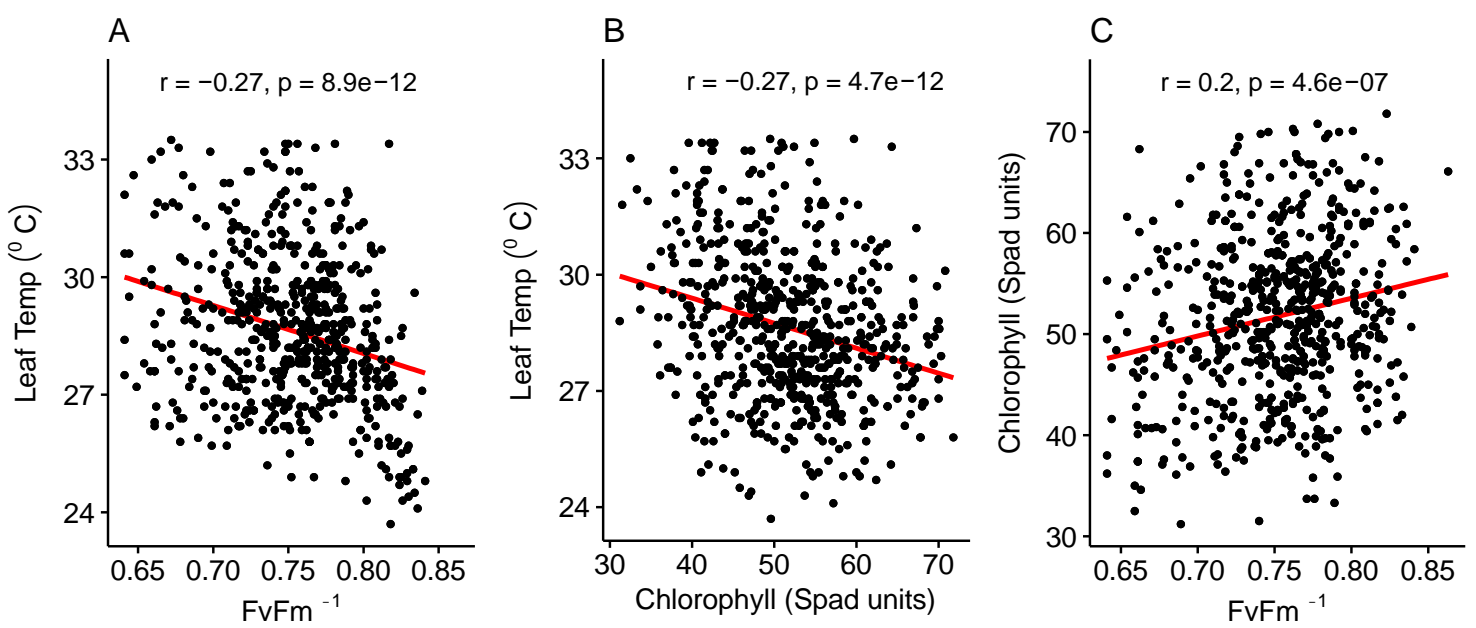

Fig 4. Correlation of stress indicator variables. A) Leaf temperature (Leaf Temp ${ }^{0} \mathrm{C}$ ) and $F_{v} F_{m}^{-1}$. B) Leaf temperature (Leaf Temp ${ }^{0} \mathrm{C}$ ) and Chlorophyll content. C) Chlorophyll content and $F_{v} F_{m}^{-1}$.

While we expected higher $\mathrm{N}$ fixing capacity and $F_{v} F_{m}^{-1}$ to increase productivity, the response was relatively lower in nitrogen treatment than osmotic stress treatments. The relatively lower biomass and increased nodulation response to $\mathrm{N}$ suggests a trade-off for increased investment in the need for physiological response and $\mathrm{N}$-fixation (Fig 2c, 2d). Contrary, the relatively higher biomass and leaf stress responses to osmotic treatments support the conjecture that exogenous stress compounds alleviate the need and the cost of metabolic response, thereby directing more allocation towards biomass output.

\subsection{Effect of non-hormonal biostimulant and sorbitol on cowpea}

Biostimulants, since its invention, definition and development over the past four decade have been shown to improve stress resistance and promote plant development (Russo and Berlyn, 1991). Although drought avoidance by hydraulic controls (Hall and Schulze, 1980; Turk and Hall, 1980) and paraheliotropism (Schakel and Hall, 1979)(also observed in this study) persist in cowpea, osmoadaptation through metabolite accumulation has been reported recently as a more conservative strategy in cowpea (Goufo et al., 2017). From our results, we conjecture that exogenous osmotic stress compounds may alleviates the metabolic need and cost towards osmoadaptation, thereby making available more photoassimilates for

390 biomass allocation.

391 Among 88 metabolites studied in cowpea cultivars by Goufo et al. (2017), only proline, galactinol and a 392 quercetin derivatives were reported beneficial to yield, whereas myoinositol and arginine were not.

393 Contrary from our findings, myoinositol and arginine, both key components of the non-hormonal 
394 Biostimulant to impacted cowpea yield. Further, we report the first yield effects of exogenous sorbitol on

395 cowpea. While sorbitol does not constitute reported osmolytic compound in osmotic stressed cowpea, its

396 yield effect in our study suggests metabolite-yield relation may be non-specific.

\subsection{Implication of the Limiting-Stress-Elimination-Hypothesis in Savanna legume agroecosystems} According to the proposed LSEH, when the limiting stress is eliminated, stress impact is relieved (Fig 5), until the next available stress becomes most limiting. The scope of this study here is not to establish the most limiting stress in cowpea. Instead, we have demonstrated which, among osmotic stress and low soil

402 N limits cowpea productivity by showing whose 'elimination' (by treatment) relatively improve 403 productivity.

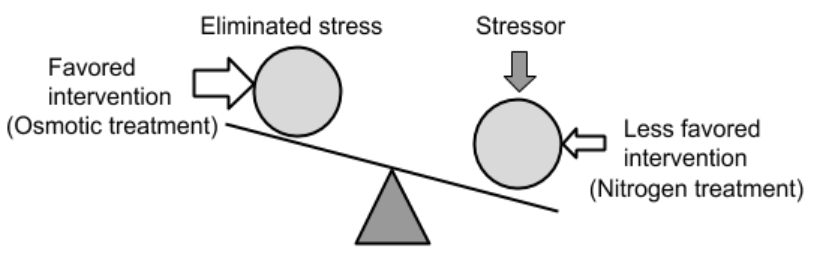

Figure 5. A schematic of limiting-stress-elimination hypothesis (LSEH). Here, a favored intervention shows sensitivity to stress response by plant, eliminate or alleviates the impact of stressor, and results in increased productivity indicated by upward tilt analogous to a "lighter weight effect".

Agroecology is a sustainable approach to crop production by additionally promoting the ecological

412 footprint of agronomy. Increasing legume production constitute a long-term food security initiative and

413 ecological restoration strategy whereby legumes improve soil $\mathrm{N}$, increase availability of percent arable

414 lands and the possible recruitment or cultivation of less competitive but essential non-legume plants or

415 crop species in the savanna. In our study, we measured N-fixation marker by nodulation capacity and

416 mean nodule dry mass. While $\mathrm{N}$ treatment relatively increased nodulation capacity significantly, the

417 effect of $\mathrm{N}$ treatment and osmotic treatment on mean nodule dry mass did vary significantly. Thus,

418 exogenous osmotic stress treatment constitute a promising alternative for increasing cowpea production

419 without impairing their biological $\mathrm{N}$-fixing capacity. $\mathrm{N}$-fixation is an important ecological process and 
more critical, in low vegetated semi-arid ecosystems such as Guinea savanna. However, the necessity to use $\mathrm{N}$ fertilizers as supplemental input to maximize legume yield should depend on whether additional inorganic $\mathrm{N}$ supplement addresses the prevailing limitation to growth. Evidence exist to question the relevance of $\mathrm{N}$ fertilization in cowpea. For instance in a study, bacteria inoculated cowpea more than $\mathrm{N}$ fertilized cowpea improved grain productivity by increasing biological N-fixation (Martins et al. (2003). In this instance, regardless of $\mathrm{N}$ supplement, increased biological $\mathrm{N}$-fixation through bacterial inoculation accounted for higher relative growth. Essentially, the metabolic cost of microbial aided N-fixation may be lower than the metabolic cost of converting inorganic $\mathrm{N}$ fertilizers to chemically useful forms impact higher crop yield. Similarly, in our study, minimizing the cost of stress allocation may have influenced yield. Thus, we conjecture two possibilities that accounts for increased growth in cowpea through exogenous stress treatments. First, osmotic treatments alleviate the metabolic need therefore the cost for osmotic stress allocation, resulting in more readily available carbon reserve. Second is the consequential decline for the need to share from the carbon pool, photosynthate allocation to neutralize stressors such as the synthesis of compatible solutes towards osmoadaptation. In both conjectures, more carbon is made ready for biomass allocation than towards defense.

In allocation theories, plants constrained under limited resources broadly tend to exhibit either defensive or reproductive allocation strategy. LSEH is an intervention for defensive allocation that satisfies the Resource Allocation Theory. Contrary, $\mathrm{N}$ fertilization represents an ideal intervention where plant strategy satisfies the Carbon-Nitrogen-Balance hypothesis. The LSEH differ from the Spregel-Liebig concept only by the intervention approach whereby in the latter, supplementing nutrient deficient plants by sufficient amounts of various limiting nutrients may have been the considerable intervention.

441 However, as exception to legumes with innate capacity to fix a degree of atmospheric $\mathrm{N}_{2}$ even when soil

$442 \mathrm{~N}$ is limited, the LSEH focuses on the principal limiting stressor, in this case, osmotic stress.

443 It can be inferred from biomass responses that a less productive outcome may ensue when a relatively

444 more limiting factor persist while an intervention is targeted at a relatively less limiting factor, such as

445 soil $\mathrm{N}$ fertilization, as the common practice by cowpea growers in Northern Ghana. Hence, it becomes

446 imperative for the agronomist to determine what constitute the measurable limiting factor to any crop of

447 interest. When that is determined, management techniques and tools that improve resource use efficiency

448 become the next relevant agronomic asset (Chaves te al, 2009). The LSEH utilizes a cost-benefit utility

449 that should inform decisions and potential innovations entrenched in the principle of efficiency and

450 sustainability in agricultural practices particularly, in regions challenged by both limited economic and

451 environmental constraints.

452 We have demonstrated through our study that intervention towards osmotic stress alleviation can

453 improved cowpea biomass allocation compared to $\mathrm{N}$ fertilization. In the search for sustainable 
454 agroecological solutions, LSEH can assist agronomist to decipher appropriate interventions optimal for

455 improving productivity.

\subsection{Conclusion}

Crops growing in Guinea savanna are constrained by a myriad of abiotic stressors such as soil Nlimitation and osmotic stressors such as drought and high temperature. Eliminating such constraints may ideally require multiple interventions. However, limited economic incentives makes this impractical, especially in low-income economies. Fertilizer remains the predominant approach to maximize crop productivity yet can be economically and environmentally unsustainable. This study proposes and tests

463 the Limiting-stress-elimination hypothesis (LSEH), which posits that eliminating the limiting factor

464 sufficiently maximizes productivity where other competing constraints exists.

In our study, we treated cowpea with a non-hormonal biostimulant and exogenous metabolite to alleviate osmotic stress. Further, we supplemented cowpea with inorganic $\mathrm{N}$ to alleviate soil N-limitation. From

467 the results, osmotic stress treatments more than $\mathrm{N}$ treatment increased cowpea productivity, assessed by 468 total biomass output and pod yield.

469 The study further implies that osmotic stress is more limiting than $\mathrm{N}$ in cowpeas under Guinea savanna 470 conditions. The study validates LSEH, which underscores the importance crop nutritional intervetion that 471 targets non-nutrient limiting abiotic stressors in-leu of fertilizer inputs even for $\mathrm{N}$-demanding systems 472 such legumes.

\section{Reference}

475 Bates, D., Mächler, M., Bolker, B., and Walker, S. (2015). Fitting Linear Mixed-Effects Models Using lme4. J Stat Softw 67, 1-48. doi:10.18637/jss.v067.i01.

477 Bryan, J. A., Berlyn, G. P., and Gordon, J. C. (1996). Toward a new concept of the evolution of symbiotic nitrogen fixation in the Leguminosae. Plant Soil 186, 151-159. doi:10.1007/BF00035069.

Buah, S.S.J and Mwinkaara, S. (2009). Response of Sorghum to Nitrogen Fertilizer and Plant Density in the Guinea Savanna Zone. J Agron. Available at: http://docsdrive.com/pdfs/ansinet/ja/0000/1153711537.pdf [Accessed April 17, 2018].

483 Crop Water Stress Index with variable irrigation and nitrogen supply. Irrig Sci 35, 549-560. doi:10.1007/s00271-017-0558-4. 
Chapin, F. S., Bloom, A. J., Field, C. B., and Waring, R. H. (1987). Plant Responses to Multiple Environmental Factors. Bioscience 37, 49-57. doi:10.2307/1310177.

Chaves, M. M., Flexas, J., and Pinheiro, C. (2009). Photosynthesis under drought and salt stress: regulation mechanisms from whole plant to cell. Ann Bot 103, 551-560. doi:10.1093/aob/mcn125.

Coley, P. D., Bryant, J. P., and Chapin, F. S. (1985). Resource Availability and Plant Antiherbivore Defense. Science (80- ) 230, 895-899. Available at: http://linksjstor.org/sici?sici=00368075\%2819851122\%293\%3A230\%3A4728\%3C895\%3ARAAPAD\%3E2.0.CO\%3B2-J [Accessed June 13, 2018].

Dakora, F. D., and Keya, S. O. (1997). Contribution of legume nitrogen fixation to sustainable agriculture in Sub-Saharan Africa. Soil Biol Biochem 29, 809-817. doi:10.1016/S0038-0717(96)00225-8.

Duranti, M., and Gius, C. (1997). Legume seeds: protein content and nutritional value. F Crop Res 53, 31-45. doi:10.1016/S0378-4290(97)00021-X.

Dwivedi, S. L., Siddique, K. H. M., Farooq, M., Thornton, P. K., and Ortiz, R. (2018). Using

FAO (2005). Fertilizer use by crop in Ghana Fertilizer use by crop in Ghana FOOD AND AGRICULTURE ORGANIZATION OF THE UNITED NATIONS Land and Plant Nutrition Management Service Land and Water Development Division. Available at: http://www.fao.org/tempref/agl/agll/docs/fertuseghana.pdf [Accessed April 17, 2018].

Goufo, P., Moutinho-Pereira, J. M., Jorge, T. F., Correia, C. M., Oliveira, M. R., Rosa, E. A. S., et al. (2017). Cowpea (Vigna unguiculata L. Walp.) Metabolomics: Osmoprotection as a Physiological Strategy for Drought Stress Resistance and Improved Yield. Front Plant Sci 8, 586. doi:10.3389/fpls.2017.00586.

Gyasi, E. A. (1995). Farming in Northern Ghana. ILEIA Newsl 11. Available at: http://citeseerx.ist.psu.edu/viewdoc/download?doi=10.1.1.556.8332\&rep=rep1\&type=pdf [Accessed April 17, 2018].

518 Lerdau, M., and Gershezon, J. (1997). Plant resource allocation., eds. F. A. (Fakhri A. . Bazzaz and J. 
(John) Grace Academic Press Available at: https://books.google.com.gh/books?id=ALlyTs1j9QC\&dq=info:t7j59RIRCsQJ:scholar.google.com\&lr=\&source=gbs_navlinks_s [Accessed April 19, 2018].

Liebig, von J. (1840). Organic chemistry in ites applications to agriculture and physiology. 1st ed. London: Taylor \& Walton.

Loomis, W. . (1932). Growth-Differentiation Balance vs Carbohydrate-Nitrogen Ratio. Proc Am Soc Hortic Sci 29, 240-245.

Martey, E., Wiredu, A. N., Etwire, P. M., Fosu, M., Buah, S. S. J., Bidzakin, J., et al. (2013). Sustainable agriculture research SAR. CCSE Available at: http://www.ccsenet.org/journal/index.php/sar/article/view/32958/19089 [Accessed April 17, 2018].

Martins, L. M. V., Xavier, G. R., Rangel, F. W., Ribeiro, J. R. A., Neves, M. C. P., Morgado, L. B., et al. (2003). Contribution of biological nitrogen fixation to cowpea: a strategy for improving grain yield in the semi-arid region of Brazil. Biol Fertil Soils 38, 333-339. doi:10.1007/s00374-003-0668-4.

Maxwell, K., and Johnson, G. N. (2000). Chlorophyll fluorescence-a practical guide. J Exp Bot 51, 659668. doi:10.1093/jexbot/51.345.659.

McAuliffe, C., Chamblee, D. S., Uribe-Arango, H., and Woodhouse, W. W. (1958). Influence of Inorganic Nitrogen on Nitrogen Fixation by Legumes as Revealed by N151. Agron J 50, 334. doi:10.2134/agronj1958.00021962005000060014x.

Mitscherlich, E. A. (1909). The law of the minimum and the law of diminishing soil productivity (In German). Landwirtsch Jahrbucher 38, 537-552.

Munns, R. (2002). Comparative physiology of salt and water stress. Plant, Cell Environ 25, 239-250. doi:10.1046/j.0016-8025.2001.00808.x.

R Core Team R: The R Project for Statistical Computing. Available at: https://www.r-project.org/ [Accessed April 17, 2018].

Richardson, A. D., Duigan, S. P., and Berlyn, G. P. (2002). An evaluation of noninvasive methods to estimate foliar chlorophyll content. New Phytol 153, 185-194. doi:10.1046/j.0028646X.2001.00289.x.

Roberts, P. A. (2013). Genetic improvements of cowpea to overcome biotic stress and drought constraints to grain productivity. Available at: https://www.canr.msu.edu/legumelab/uploads/files/Technical_Description_SO1_A5_R1_Roberts_9 _13_13.pdf [Accessed September 15, 2018].

Rodríguez, V. M., Soengas, P., Alonso-Villaverde, V., Sotelo, T., Cartea, M. E., and Velasco, P. (2015). Effect of temperature stress on the early vegetative development of Brassica oleracea L. BMC Plant Biol 15, 145. doi:10.1186/s12870-015-0535-0. 
Runge-Metzger, A., Diehl, L., and Nyankpala Agricultural Experiment Station. (1993). Farm household systems in northern Ghana: a case study in farming systems oriented research for the development of improved crop production systems. J. Margraf Scientific Books.

Russo, R. O., and Berlyn, G. P. (1991). The Use of Organic Biostimulants to Help Low Input Sustainable Agriculture. J Sustain Agric 1, 19-42. doi:10.1300/J064v01n02_04.

Salvagiotti, F., Cassman, K. G., Specht, J. E., Walters, D. T., Weiss, A., and Dobermann, A. (2008). Nitrogen uptake, fixation and response to fertilizer N in soybeans: A review. F Crop Res 108, 1-13. doi:10.1016/J.FCR.2008.03.001.

Schakel, K., and Hall, A. (1979). Reversible Leaflet Movements in Relation to Drought Adaptation of

Tilman, D. (2001). Forecasting Agriculturally Driven Global Environmental Change. Science (80- ) 292, 281-284. doi:10.1126/science.1057544.

Tilman, D., Cassman, K. G., Matson, P. A., Naylor, R., and Polasky, S. (2002). Agricultural sustainability and intensive production practices. Nature 418, 671-677. doi:10.1038/nature01014.

Turk, K. J., and Hall, A. E. (1980). Drought Adaptation of Cowpea. II. Influence of Drought on Plant Water Status and Relations with Seed Yield1. Agron J 72, 421. doi:10.2134/agronj1980.00021962007200030005x.

Udompetaikul, V., Upadhyaya, S. K., Slaughter, D., Lampinen, B., Shackel, K., and House Louisville, G. Written for presentation at the 2011 ASABE Annual International Meeting Sponsored by ASABE. ASABE Annu Int Meet. Available at: https://pdfs.semanticscholar.org/dd23/5e29eaac3dfbfd0973bb3cc08df5e3187e58.pdf [Accessed July 9, 2018].

van der Ploeg, R. R., Bo“hm, W., and Kirkham, M. B. (1999). On the Origin of the Theory of Mineral Nutrition of Plants and the Law of the Minimum. Soil Sci Soc Am J 63, 1055. doi:10.2136/sssaj1999.6351055x.

Vitousek, P. M., Aber, J. D., Howarth, R. W., Likens, G. E., Matson, P. A., Schindler, D. W., et al. (1997). HUMAN ALTERATION OF THE GLOBAL NITROGEN CYCLE: SOURCES AND CONSEQUENCES. Ecol Appl 7, 737-750. doi:10.1890/10510761(1997)007[0737:HAOTGN]2.0.CO;2.

Wiegand, C. L., and Namken, L. N. (1966). Influences of Plant Moisture Stress, Solar Radiation, and Air Temperature on Cotton Leaf Temperature1. Agron J 58, 582. 
bioRxiv preprint doi: https://doi org/10.1101/594754; this version posted March 31, 2019. The copyright holder for this preprint (which was not certified by peer review) is the author/funder, who has granted bioRxiv a license to display the preprint in perpetuity. It is made available under aCC-BY-NC-ND 4.0 International license. 